\title{
Summer mortality: effects on the distribution and abundance of the acorn barnacle Tetraclita japonica on tropical shores
}

\author{
Benny K. K. Chan ${ }^{1,4}$, David Morritt ${ }^{2}$, Maurizio De Pirro ${ }^{3}$, Kenneth M. Y. Leung ${ }^{2,5}$, \\ Gray A. Williams ${ }^{1, *}$ \\ ${ }^{1}$ The Swire Institute of Marine Science, Department of Ecology \& Biodiversity, The University of Hong Kong, \\ Pokfulam Road, Hong Kong, SAR \\ ${ }^{2}$ School of Biological Sciences, Royal Holloway, University of London, Egham, Surrey TW20 0EX, UK \\ ${ }^{3}$ Dipartimento di Biologia Animale e Genetica, Università degli Studi di Firenze, Firenze, Italy \\ ${ }^{4}$ Present address: Research Centre for Biodiversity, Academia Sinica, Taipei 115, Taiwan \\ ${ }^{5}$ Present address: The Swire Institute of Marine Science, Department of Ecology \& Biodiversity, The University of Hong \\ Kong, Pokfulam Road, Hong Kong, SAR
}

\begin{abstract}
In the Hong Kong rocky intertidal, the demography of the acorn barnacle Tetraclita japonica is largely determined by regular, intense mortality events in the summer and subsequent pulses of recruitment in late summer. During 2 consecutive summers from 2000 to 2001, 34 to 52 and 98 to $99 \%$ of $T$. japonica were killed on the mid- and high shore, respectively, with younger cohorts suffering higher mortality in the mid-shore. Recruitment of $T$. japonica occurs in late summer; as a result, the population in the high shore consists of a single cohort of new recruits, while the mid-shore supports 2 cohorts (new recruits and adult survivors). To investigate how thermal stress affects acorn barnacle populations, air and rock temperatures and sub-lethal physiological measures (body temperature, sinus pulsation rate and haemolymph osmolality) of $T$. japonica were taken on the mid- and high shore during daytime, low spring tides in June-July 2001. Mean body temperature increased gradually after emersion, reaching a maximum of $\sim 48^{\circ} \mathrm{C}$ at noon, 6 to $8^{\circ} \mathrm{C}$ higher than the adjacent rock surface. T. japonica entered a heat-induced coma when body temperatures reached $45^{\circ} \mathrm{C}$. Osmolality of the haemolymph and sinus pulsation rate increased with body temperature as a result of water loss and possibly altered haemolymph pressure; both were greater in high than in mid-shore individuals, with barnacles on horizontal surfaces being hotter than those on vertical surfaces. Body temperature and sinus pulsation rate differed between shore levels, but were similar at spatial scales of 1 to $20 \mathrm{~m}$ at the same tidal height. Haemolymph osmolality, however, varied over this distance, probably due to individual variation in the amount of mantle water trapped before emersion and possible micro-habitat differences. Heat and desiccation stress, therefore, play an important role in determining the life history of $T$. japonica by limiting their distribution and abundance and influencing the demography of the population at different spatial scales.
\end{abstract}

KEY WORDS: Barnacle $\cdot$ Tetraclita $\cdot$ Summer mortality $\cdot$ Distribution Resale or republication not permitted without written consent of the publisher

\section{INTRODUCTION}

Mortality events are an important component of species' life histories as they reduce population size and influence population distribution, structure and persistence. Such mortality events range from predictable regular events including old age or predation, to nonpredictable pulse events such as storm damage or ice scouring (reviewed by Barnes 1999). The abundance and structure of barnacle populations have an important influence on intertidal community dynamics as, being sessile, they are major space occupiers and play 
a role as foundation species on rocky shores (Bertness et al. 1998). Mortality in barnacles is typically heavy during the larval settlement and early post-settlement stages, and such mortality events therefore play important roles in affecting the subsequent distribution, abundance and population dynamics of barnacle populations (Sutherland 1987, reviewed by Barnes 1999). Juvenile and adult mortality rates are, however, generally much lower (see review in Barnes 1999) than those experienced during the larval and settlement phases.

In physically harsh environments, juveniles and adults may also suffer intense mortality events, resulting in a substantial decrease in population abundance and limiting overall distribution patterns on the shore (Ellis \& Wilce 1961, Bertness et al. 1999). In the polar intertidal zone, for example, seasonal ice scouring and freezing stress causes a huge mortality of juvenile and adult Semibalanus balanoides, and only individuals living in crevices can survive through the winter period (Ellis \& Wilce 1961, McCook et al. 1997). On extremely exposed shores in the UK and USA, strong waves can dislodge the dense and elongated forms of S. balanoides and result in $90 \%$ mortality of the population (Bertness 1989).

In tropical regions, the rocky intertidal zone often experiences prolonged and intense solar radiation and can be considered a physically stressful environment (sensu Menge \& Sutherland 1987, Williams 1994). Heat and desiccation stress can affect the behaviour and distribution of rocky shore organisms (Garrity 1984, Williams \& Morritt 1995, Williams et al. 2005), causing species to take refuge from physical stress in microhabitats where air and rock temperatures are reduced (Garrity 1984, Williams \& Morritt 1995). In Hong Kong, rock surface temperatures $>50^{\circ} \mathrm{C}$ are common on calm summer days during daytime low spring tides (Williams \& Morritt 1995). To avoid intense solar radiation, high evaporation and limited wave splash, mobile species seek refuge in safe microhabitats (vertical rock surfaces, rock pools and crevices), whereas those that remain on horizontal surfaces often perish (Williams 1994, Williams \& Morritt 1995, Williams \& McMahon 1998, Williams et al. 2005, unpubl. data). Sessile organisms such as barnacles can potentially experience even higher mortality risks than their mobile counterparts during the summer as they cannot seek refuge in less stressful habitats and are restricted to their original settlement location (Williams \& Morritt 1995, Chan et al. 2001). Although heavy pulse mortalities of species assemblages have been reported during summer on tropical shores (e.g. limpets, Williams \& Morritt 1995; barnacles, Chan et al. 2001), few studies have focused on the effects of such events on population structure, or the sub-lethal responses and physiological state of the organisms under intense heat stress (but see South- ward 1958, 1962, Foster 1969, 1971, Wethey 1984 on temperate species).

The acorn barnacle Tetraclita japonica is the major space occupier ( $>40 \%$ cover) in the Hong Kong midintertidal and is abundant from mid- to high shore (Chan 2001, Chan et al. 2001, Chan \& Williams 2004). Cyprids of $T$. japonica settle on the shore during late summer when both thermal stress and bulldozing by grazers affect their post-settlement mortality and consequently their initial distribution (Chan 2003, Chan \& Williams 2003). Juveniles and adults can also experience mortality events in summer (Chan et al. 2001); however, the effects of such events are still poorly understood. The objectives of the present study, therefore, were to describe the spatial and temporal physiological responses of $T$. japonica during periods of thermal and desiccation stress and how summer mortality events influence population structure of this species on Hong Kong shores.

\section{MATERIALS AND METHODS}

Study sites and timing. Studies were conducted on a south-facing exposed shore at Cape d'Aguilar Marine Reserve (Hong Kong; $22^{\circ} \mathrm{N}, 114^{\circ} \mathrm{E}$ ) during 2 consecutive summers (April to August) in 2000 and 2001. The shore is composed of granodiorite and supports high densities of Tetraclita japonica (Chan et al. 2001). T. japonica is most abundant from $\sim 1.75$ to $2.0 \mathrm{~m}$ above Chart Datum (CD), and the upper limit is at $\sim 2.25$ to $2.5 \mathrm{~m}$ above CD (Chan et al. 2001). Shores in Hong Kong are influenced by strong seasonal variation in climate; the summer is hot and wet (April to September; mean air temperature $30^{\circ} \mathrm{C}$ ), while winter is cool and dry (October to March; mean air temperature $15^{\circ} \mathrm{C}$; Kaehler \& Williams 1996). Tides in Hong Kong are mixed semi-diurnal with a maximum tidal range of $\sim 2.5 \mathrm{~m}$, and the lowest, low spring tides occur during the afternoon in summer (Morton et al. 1996). As a result, intertidal assemblages in Hong Kong summers are exposed to long periods ( $6 \mathrm{~h})$ of intense solar radiation during daytime spring tides (Williams \& Morritt 1995).

Population structure of Tetraclita japonica. Variation in the population structure of T. japonica was studied along a $20 \mathrm{~m}$ stretch of shoreline. Sampling was conducted at six $25 \mathrm{~cm}$ vertical intervals $(1.25$ to $2.5 \mathrm{~m}$ above $\mathrm{CD}$ ) to cover the vertical range of $T$. japonica. At each level, ten $25 \times 25 \mathrm{~cm}$ quadrats were randomly positioned and a digital photograph taken using a photoframer (see Chan \& Williams 2003 for details). The basal rostral-carinal (rc) diameter of the barnacles (Chan et al. 2001) was measured from the calibrated photographs using Sigma Scan Pro (SYSTAT). Sam- 
pling was conducted once in April (early summer) and once in August (mid-summer) in both 2000 and 2001. The number and size of cohorts were estimated from size-frequency histograms using ELEFAN (Electronic Length Frequency Analysis, ICLARM, Philippines, see also Chan \& Williams 2004).

Diurnal variation in rock surface and barnacle body temperatures. Diurnal variation in physical stresses in different microhabitats was assessed by measuring the body temperature of barnacles and the temperature of rock surfaces adjacent to individuals during daytime low spring tides. A $10 \mathrm{~m}$ stretch of shoreline was chosen with horizontal $\left(<45^{\circ}\right.$ inclination) and vertical ( $>45^{\circ}$ inclination, see Williams \& Morritt 1995) rock surfaces in the high shore and sloping platforms in the mid and low shores. Investigations were conducted at 2 tidal levels, $2.25 \mathrm{~m}$ above CD (the upper limit of Tetraclita japonica) and $1.75 \mathrm{~m}$ above CD (the abundant zone of $T$. japonica $=$ Tetraclita-dominated zone). To investigate variation in thermal stress among different microhabitats, 10 barnacles (basal diameter 12 to $18 \mathrm{~mm}$ ) were located every $1 \mathrm{~h}$ (from 09:00 to 17:00 h) using a random number table on both vertical and horizontal rocks at $2.25 \mathrm{~m}$ above CD on 27 June 2000 (average air temperature $=29.2^{\circ} \mathrm{C}$; total bright sunshine $=10.2 \mathrm{~h}$, Hong Kong Observatory). To compare thermal stress between tidal levels, an additional 10 barnacles (basal diameter 12 to $18 \mathrm{~mm}$ ) were also located hourly from the Tetraclita-dominated zone. The rock surface temperature adjacent to the chosen barnacle (within $2 \mathrm{~cm}$ ) and barnacle body temperature (by inserting the thermocouple through the opercular plates) were measured in situ using a digital thermocouple (K-type thermocouple, $0.1 \mathrm{~mm}$ diameter, TES digital thermometer, $\pm 0.1^{\circ} \mathrm{C}$ ).

Physiological state of Tetraclita japonica during daytime low tides. The physiological status of barnacles was measured along $10 \mathrm{~m}$ transects at both 2.25 and $1.75 \mathrm{~m}$ above CD on 21 June 2001 (average air temperature $=29.4^{\circ} \mathrm{C}$; total bright sunshine $=8.3 \mathrm{~h}$, Hong Kong Observatory). Five barnacles (basal diameter 12 to $18 \mathrm{~mm}$ ) were selected randomly each hour from 11:00 to 17:00 h (except at 16:00 h due to time limitations). The temperature of the rock surface adjacent to the barnacle and the barnacle body temperature were measured as described above. The barnacles were then collected on rock chips using a hammer and chisel, kept on ice and transported to the Swire Institute of Marine Science, within 2 min of collection. During transfer, barnacle tissues were not in direct contact with the ice so any effect on osmotic concentration of either mantle water or haemolymph was considered negligible. The water in the mantle cavity and haemolymph from the rostral sinus were collected using siliconised glass capillary tubes (Chan et al. 2001).
Samples were temporarily stored over ice in microcentrifuge tubes before measuring osmolality in $10 \mu \mathrm{l}$ samples using a vapour pressure osmometer (Wescor 5520). The osmometer was regularly calibrated against Wescor 290 and 1000 mOsm kg ${ }^{-1} \mathrm{NaCl}$ standards.

To investigate variation in haemolymph osmolality between different size classes, an additional 10 barnacles from 2 different size classes (12 to 18 and 24 to $27 \mathrm{~mm})$, which represent the 2 major cohorts in the population (Chan \& Williams 2004), were also sampled at $15: 15$ and $17: 15 \mathrm{~h}$ on the same day. A further 10 barnacles were selected from the 2 tidal levels at 12:00 (noon, maximum solar radiation) and 16:00 h (late afternoon, reduced solar radiation) to investigate variation in sinus pulsation rate and haemolymph osmolality. Sinus pulsation rate (beats $\mathrm{s}^{-1}$ ) was measured in situ from these 40 individuals using the noninvasive method developed by Depledge \& Andersen (1990). The location of the rostral sinus was determined from laboratory trials both in air and under water in order to distinguish respiratory movement (such as cirral activity, see Crisp \& Southward 1961) from sinus pulsation. On the shore, an infrared sensor was fixed to the opercular opening of the barnacles using Blue-Tac (Bostick) and the infrared reflection of the rhythmical sinus pulsation was amplified, filtered and the signal obtained was visualized and recorded on a Portable Oscilloscope (Fluke 192 USA, see Chelazzi et al. 1999 for technical details). The barnacles were then collected for haemolymph sampling and osmolality measurements following the methods described previously. Variation in haemolymph osmolality and sinus pulsation rate between tidal levels (fixed factor) and time (fixed factor) were analysed using 2-factor ANOVA.

Spatial variation in physiological responses. Physiological measurements were also made between 13:00 and 15:00 h (representing the noon and late afternoon periods, Williams \& Morritt 1995) on 4 July 2001 during a calm day with a low spring tide (average air temperature $29.7^{\circ} \mathrm{C}$; total bright sunshine $=9 \mathrm{~h}$; Hong Kong Observatory). To investigate variation in levels of stress on different spatial scales, response variables were measured at spatial scales within metres, between metres and between tens of metres in the Tetraclita-dominated zone $(1.75 \mathrm{~m}$ above CD). Two $10 \mathrm{~m}$ transects, separated by $20 \mathrm{~m}$, were established, and within each transect, 3 random $25 \times 25 \mathrm{~cm}$ areas (at least $2 \mathrm{~m}$ apart) were located; two $10 \times 10 \mathrm{~cm}$ plots were then established within each area. Within each $10 \times 10 \mathrm{~cm}$ plot, response variables were taken from 4 randomly selected Tetraclita japonica individuals (4 barnacles per quadrat being the maximum number from which sinus pulsation rates could be determined within the tidal emersion period). The body tem- 
peratures of $T$. japonica, rock surface temperatures, adjacent air temperatures, and barnacle sinus pulsation rate and haemolymph osmolality were measured as described above. A three-factor (Area, Transect, Quadrat; all random factors) nested ANOVA was used to investigate the relative importance of these different spatial scales.

\section{RESULTS}

\section{Population structure of Tetraclita japonica}

The population structure of Tetraclita japonica varied between tidal levels (Fig. 1). In May 2000 in the Tetraclita-dominated zone, there were 2 cohorts representing 1 yr old (1999 cohort, mean \pm SD: $\sim 15 \pm$ $3.01 \mathrm{~mm}$ r-c diameter) and 2 yr old barnacles (1998 cohort, $\sim 24 \pm 2.3 \mathrm{~mm} \mathrm{r}$-c diameter). Only the 1999 cohort could be found at the upper limit, whereas on the low shore, the 1998 cohort dominated the popula- tion (Fig. 1). In summer, 98\% of the 1999 cohort had died at the upper limit, leaving empty tests on the shore (Fig. 1). In the Tetraclita-dominated zone, 52\% of the tests sampled were empty. Although individuals from both 1998 and 1999 cohorts died, the 1999 cohort in the Tetraclita-dominated zone suffered greater mortality than the 1998 cohort (Fig. 1). At the lower limit, the cohort structure was similar to the pattern shown in May and no empty tests were recorded.

After winter 2000, a new cohort (the 2000 cohort, $15 \pm$ $3.5 \mathrm{~mm}$ ) was recorded at the Tetraclita japonica upper limit in May 2001 (Fig. 1). The Tetraclita-dominated zone consisted of the 1999 cohort and the newly recruited 2000 cohort. The lower limit of T. japonica, however, still consisted of the 1998 cohort and the density was similar to that in August 2000 (Fig. 1). In summer 2001, heavy mortality was again recorded at the upper limit of T. japonica, with up to $99 \%$ of the 2000 cohort comprising empty tests (Fig. 1). The barnacles in the Tetraclita-dominated zone suffered $34 \%$ mortality, and the younger 2000 cohort experienced greater mortality
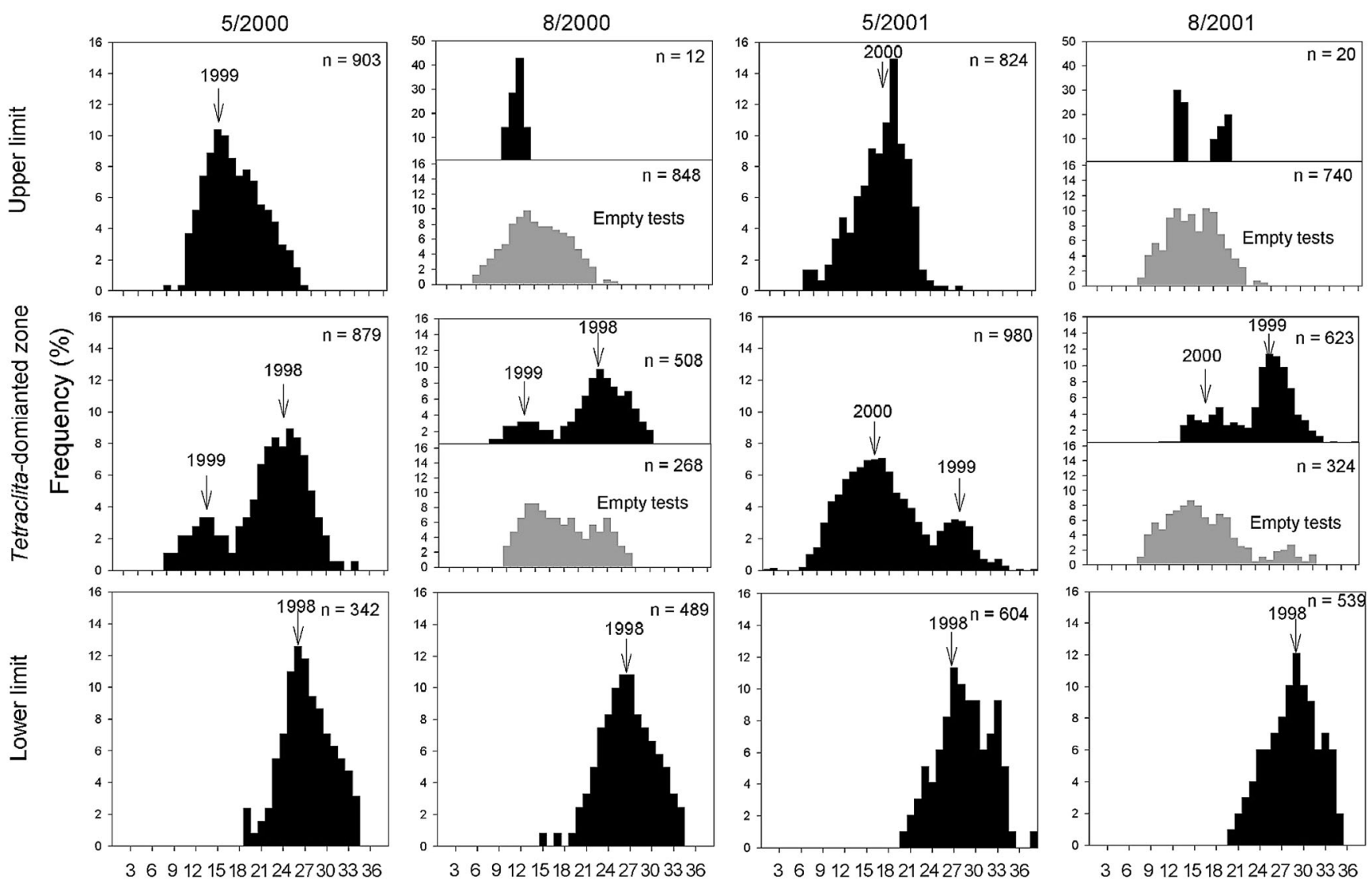

369121518212427303336

369121518212427303336

Basal rostral-carinal diameter $(\mathrm{mm})$

Fig. 1. Tetraclita japonica. Population structure (identified from the basal rostral-carinal diameter) at the upper limit (2.25 to $2.50 \mathrm{~m}$ above Chart Datum, CD), Tetraclita-dominated zone (1.75 to $2.0 \mathrm{~m}$ above CD) and lower limit (1.25 to $1.50 \mathrm{~m}$ above CD) from May 2000 to August 2001. Black bars represent live barnacles while grey bars represent empty tests. Cohorts identified using ELEFAN are indicated as 1998 (1998 cohort), 1999 (1999 cohort) and 2000 (2000 cohort) 


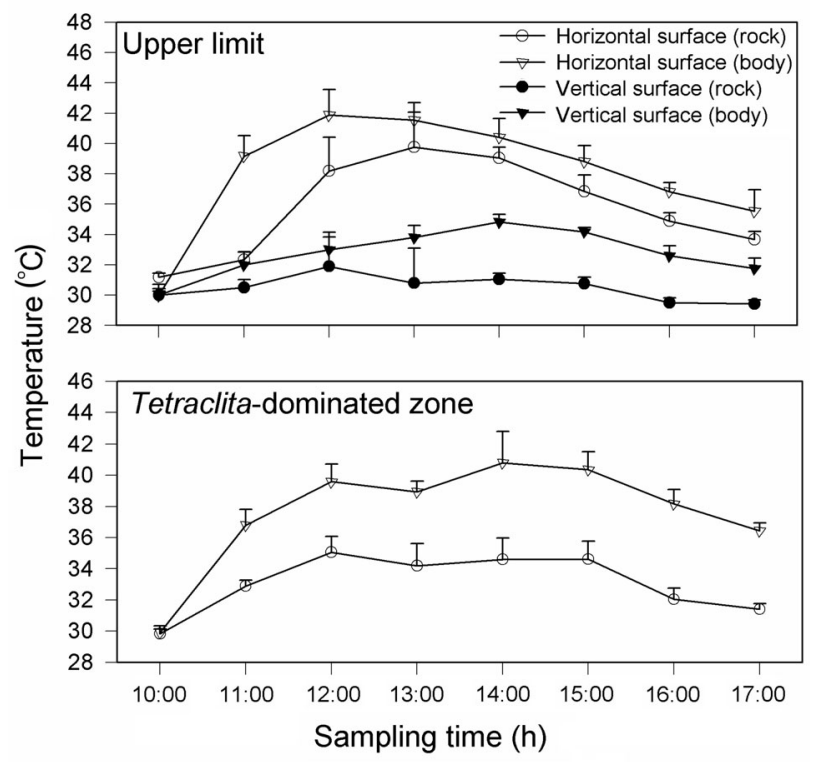

Fig. 2. Tetraclita japonica. Diurnal hourly variation in the mean $(+\mathrm{SD}, \mathrm{n}=10)$ body and rock surface temperatures on horizontal surfaces and vertical surfaces at the upper limit ( 2.25 to $2.50 \mathrm{~m}$ above $\mathrm{CD}$ ), and horizontal surfaces at the Tetraclita-dominated zone (1.75 to $2.0 \mathrm{~m}$ above CD)

than did the 1999 cohort (Fig. 1). The lower limit of $T$. japonica again showed very little change and was similar to that in the previous year (Fig. 1).

\section{Diurnal variation in body temperature}

Temperature variation of the rock surface and body of Tetraclita japonica followed a diurnal pattern (Fig. 2). In general, the body temperature of the barnacles was 4 to $6^{\circ} \mathrm{C}$ higher than rock surface temperatures (Fig. 2). At the upper limit, body temperatures of barnacles on horizontal surfaces increased from $\sim 33^{\circ} \mathrm{C}$ at 10:00 $\mathrm{h}$ to maximum levels at 12:00 h (mean body temperature $42^{\circ} \mathrm{C}$ and rock surface temperature $38^{\circ} \mathrm{C}$ ), and then decreased gradually in the afternoon (Fig. 2). Barnacles with a body temperature $>40^{\circ} \mathrm{C}$ had opercular valves slightly open and showed a very slow response to external stimulation after $2 \mathrm{~h}$ of prolonged heat stress, suggesting that they were experiencing heat-induced coma. Rock and barnacle temperatures on vertical surfaces followed a similar pattern, but were significantly lower than those recorded on horizontal surfaces (maximum body temperature: $35^{\circ} \mathrm{C}$ on vertical surfaces and $42^{\circ} \mathrm{C}$ on horizontal surfaces, $t$-test at 12:00 h: $t=-10.7, \mathrm{df}=18, \mathrm{p}<0.05$; Fig. 2). The barnacles in the Tetraclita-dominated zone also had significantly lower body temperatures than those at the upper limit (Fig. 3 ; $t$-test at 12:00 h: $t=3.38, \mathrm{df}=18$, $\mathrm{p}<0.05)$.

\section{Physiological status of Tetraclita japonica during daytime low tides}

At the upper limit of Tetraclita japonica, barnacle haemolymph osmolality (780 mOsm $\mathrm{kg}^{-1}$, seawater $\left.\sim 777 \mathrm{mOsm} \mathrm{kg}^{-1}\right)$ and body temperatures $\left(32^{\circ} \mathrm{C}\right.$, seawater $\sim 29^{\circ} \mathrm{C}$ ) increased gradually with emersion after the morning high tide (Fig. 3). Barnacle body temperature reached a maximum of $42^{\circ} \mathrm{C}$ at $14: 00 \mathrm{~h}$ and then decreased in the afternoon, while haemolymph osmolality continued to increase until the end of the sampling period (930 mOsm kg ${ }^{-1}$; Fig. 3). At the Tetraclitadominated level, mean body temperature increased from $28^{\circ} \mathrm{C}$ to a maximum of $37^{\circ} \mathrm{C}$ at $14: 00 \mathrm{~h}$ and then gradually decreased in the afternoon (Fig. 3). Haemolymph osmolality, however, remained relatively stable at $\sim 800 \mathrm{mOsm} \mathrm{kg}^{-1}$ throughout the day (Fig. 3). At noon, the barnacles at the upper limit had higher body temperatures and more concentrated haemolymph than the individuals at the lower shore level (mean body temperature $=42$ vs. $36^{\circ} \mathrm{C}$; mean haemolymph osmolality $=1000$ vs. $870 \mathrm{mOsm} \mathrm{kg}^{-1}$; Fig. 4,
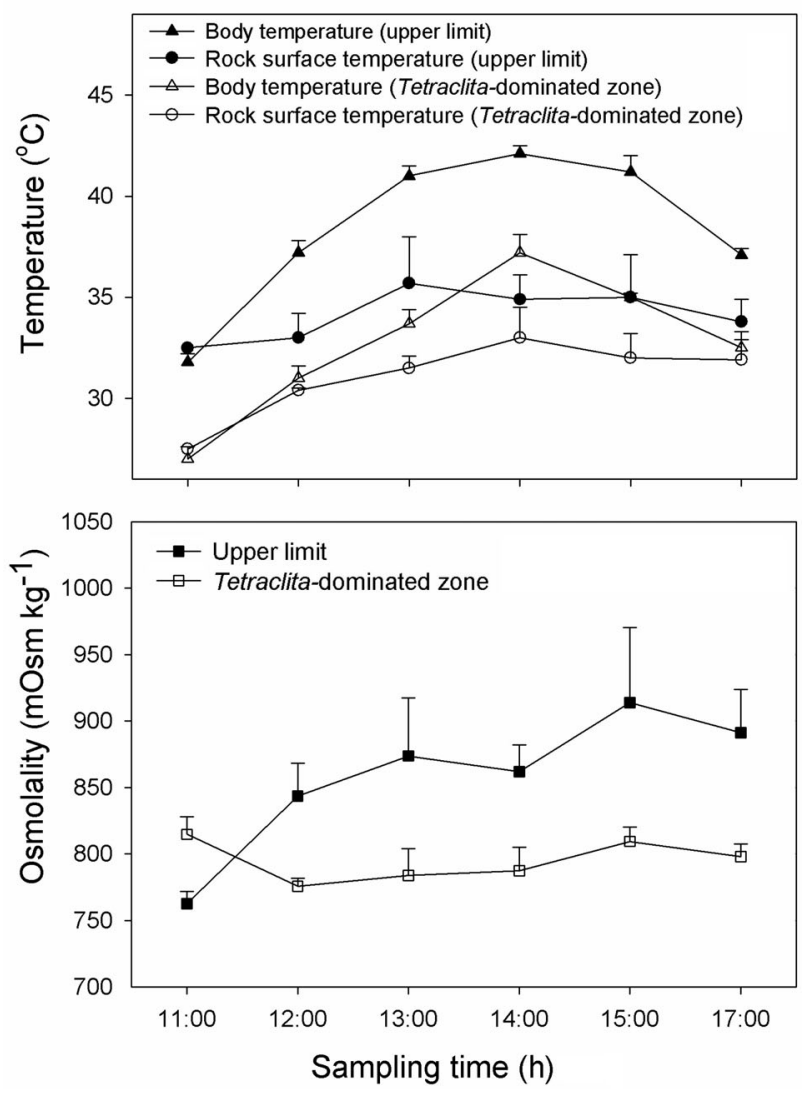

Fig. 3. Tetraclita japonica. Diurnal hourly variation in the mean $(+\mathrm{SD}, \mathrm{n}=10$ ) body temperature, rock surface temperature and haemolymph osmolality at the upper limit (2.25 to $2.50 \mathrm{~m}$ above $\mathrm{CD}$ ) and Tetraclita-dominated zone (1.75 to $2.0 \mathrm{~m}$ above $\mathrm{CD}$ ) 

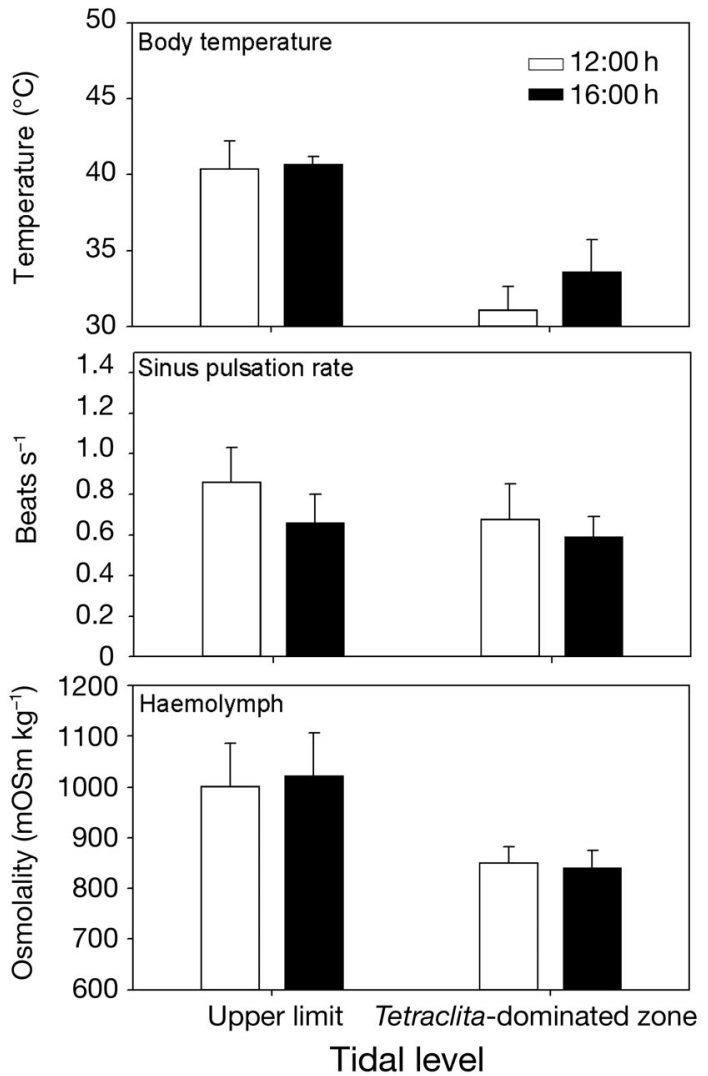

Fig. 4. Tetraclita japonica. Mean $(+\mathrm{SD}, \mathrm{n}=10)$ body temperature, sinus pulsation rate and haemolymph osmolality between the upper limit (2.25 to $2.50 \mathrm{~m}$ above CD) and Tetraclita-dominated zone (1.75 to $2.0 \mathrm{~m}$ above $\mathrm{CD}$ ) at $12: 00$ and $16: 00 \mathrm{~h}$

Table 1). Sinus pulsation rate of barnacles at their upper limit was also significantly greater than their counterparts on the lower shore, and both groups exhibited significantly higher sinus pulsation rate at noon than at 16:00 h (Fig. 4, Table 1). There was, however, no significant difference in haemolymph osmolality between large and small barnacles regardless of sampling time (2-factor ANOVA, p > 0.05 for all terms).

\section{Spatial variation in the physiological responses}

There were no significant differences in body temperature or sinus pulsation rate between transects $(20 \mathrm{~m})$, among areas $(<10 \mathrm{~m})$ or between plots within each area $(<1$ m, Fig. 5; nested ANOVA, all terms p > 0.05). Haemolymph osmolality in Tetraclita japonica, however, varied between the transects $(20 \mathrm{~m})$ and ranged from 885 to 910 mOsm kg-1 (Fig. 5; nested ANOVA: $F_{1,35}=11.19, \mathrm{p}<0.05$, all other terms $\mathrm{p}>$ 0.05). Pooling data for osmolality, sinus pulsation rate and body temperature of $T$. japonica gathered during diurnal and spatial variation measurements throughout the whole experimental period (total $\mathrm{n}=88$ ) revealed significant positive correlations between body temperature and both haemolymph osmolality and sinus pulsation rate (Fig. 6), but not, however, between haemolymph osmolality and sinus pulsation rate $(\mathrm{p}>0.05)$.

\section{DISCUSSION}

\section{Population responses}

During the summer in Hong Kong, Tetraclita japonica experiences intense heat and desiccation stress which varies spatially (between tidal levels and microhabitats), and also temporally within a day. After several hours' emersion on calm summer days, acorn barnacles in both the mid- and high shore suffer from prolonged heat and desiccation stress that can result in heavy mortality, especially at their upper distribution limit. Consequently during mid-summer (JulyAugust), a substantial proportion of the T. japonica population died. Mortality was greater in the high than mid-shore, resulting in differences in cohort structure. In 2000, only a single cohort of new recruits was recorded at the high shore and this cohort was completely removed by the following summer. In the subsequent summer, there was a new recruitment event and, as a result, in 2001, the population at this level

Table 1. Tetraclita japonica. Two-factor ANOVA to investigate variation in barnacle body temperature $\left({ }^{\circ} \mathrm{C}\right)$, haemolymph osmolality $\left(\mathrm{mOsm} \mathrm{kg}^{-1}\right.$ ) and sinus pulsation rate (beats ${ }^{-1}$ ) at 2 time intervals (12:00 and 16:00 h) between 2 tidal levels (the upper limit and Tetraclita-dominated zone). Data fulfilled the assumption of homogeneity of variance based on Cochran's $C$-tests $\left({ }^{*}\right.$ significant factors, $\left.\mathrm{p}<0.05\right)$

\begin{tabular}{|c|c|c|c|c|c|c|c|c|c|c|c|c|}
\hline & \multicolumn{4}{|c|}{ Body temperature } & \multicolumn{4}{|c|}{ Haemolymph osmolality } & \multicolumn{4}{|c|}{ Sinus pulsation rate } \\
\hline & $\mathrm{df}$ & MS & $F$ & $\mathrm{p}$ & $\mathrm{df}$ & MS & $F$ & $\mathrm{p}$ & $\mathrm{df}$ & MS & $F$ & $\mathrm{p}$ \\
\hline Time & 1 & 25.4 & 9.8 & $0.003^{*}$ & 1 & 184 & 0.05 & 0.8 & 1 & 0.17 & 7.9 & $0.007^{*}$ \\
\hline Levels & 1 & 642 & 248 & $0.0001^{*}$ & 1 & 268632 & 69 & $0.0001^{*}$ & 1 & 0.14 & 6.4 & $0.01^{*}$ \\
\hline Time $\times$ Levels & 1 & 7.6 & 2.9 & 0.09 & 1 & 2496 & 0.65 & 0.4 & 1 & 0.02 & 1.08 & 0.3 \\
\hline Residual & 36 & 2.9 & & & 36 & 3894 & & & 36 & 0.02 & & \\
\hline
\end{tabular}




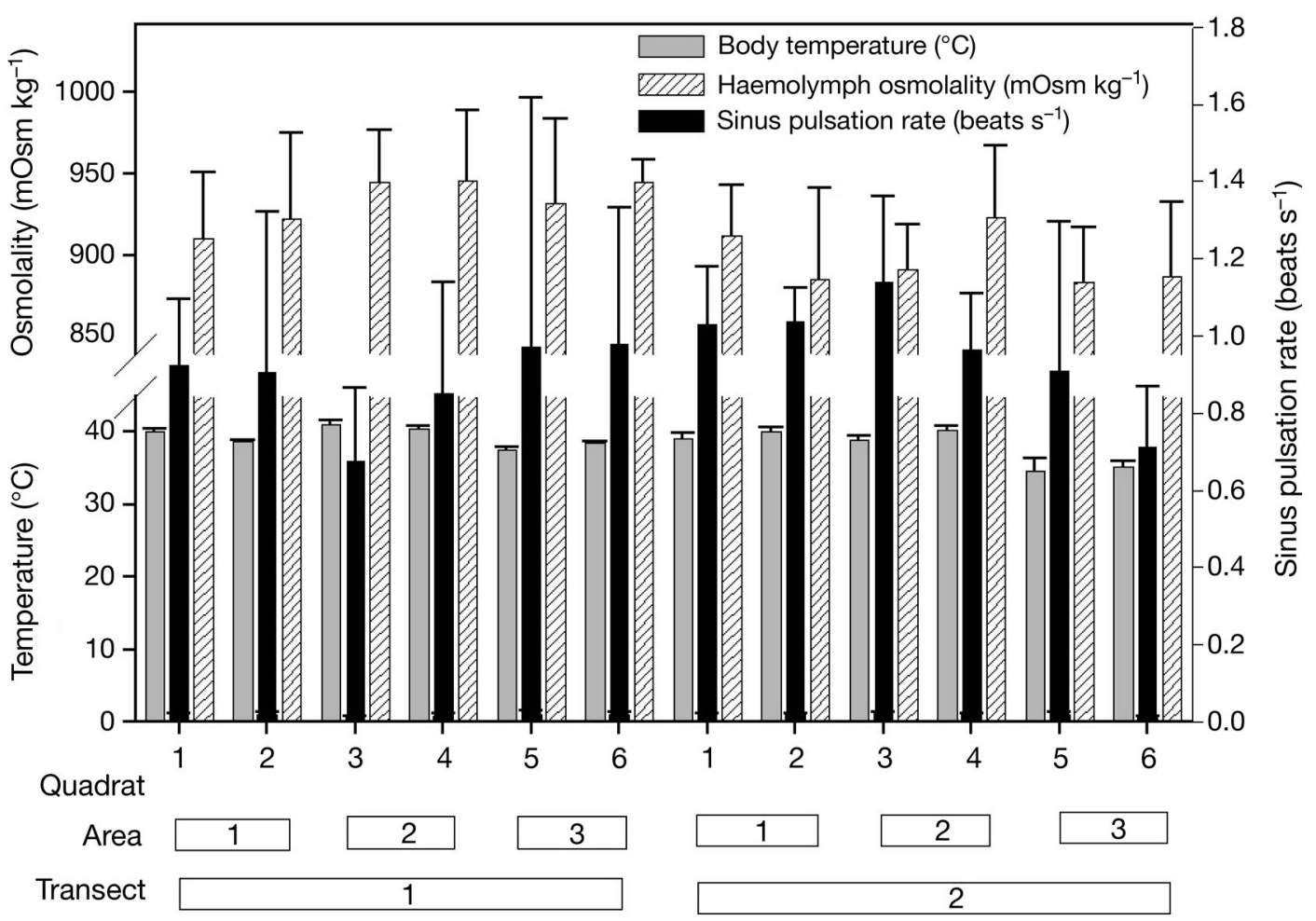

Fig. 5. Tetraclita japonica. Variation in mean $(+\mathrm{SD}, \mathrm{n}=4)$ barnacle body temperature, sinus pulsation rate and haemolymph osmolality between transects $(>20 \mathrm{~m})$, areas $(>2 \mathrm{~m})$ and quadrats $(>0.25 \mathrm{~m})$

once again comprised a single cohort of juveniles (immature individuals, $\sim 14 \mathrm{~mm} \mathrm{r-c} \mathrm{diameter,} \mathrm{Cai} \mathrm{\&}$ Huang 1986, B. K. K. Chan pers. obs.). This cohort does not, therefore, have the opportunity to reproduce before they are killed in the summer. In the Tetraclitadominated zone (mid-shore), 2 cohorts were recorded, both of which suffered summer mortality although a small proportion of juveniles and adults survived. Mortality appeared to be size-dependent, the younger cohorts suffering greater mortality than the older ones. Although there were no recorded differences in the body temperature and haemolymph osmolality between barnacles of the 2 different sizes classes, smaller barnacles are likely to have a reduced ability to tolerate physiological damage from heat and desiccation stress (e.g. Semibalanus balanoides, Ware \& Hartnoll 1996), thereby resulting in relatively higher mortality. Greater susceptibility of smaller individuals to physical stress has also been recorded in mussels (Helmuth 1998) and limpets (Williams et al. 2005). This summer mortality and subsequent recruitment pattern of $T$. japonica in tropical regions like Hong Kong are regular and predictable (see also Sutherland 1987, Helmuth \& Hofmann 2001) and were consistent over 3 yr of observations (B. K. K. Chan unpubl. data).

Barnacles from low shores did not experience intense mortality, indicating that individuals that settle at this level do not experience the same harsh physical stresses as those in the mid- and high shores. No recruitment, however, occurred at this level, the reasons for which remain unclear, although competition for space is probably not the cause as rock space does not appear to be limiting at the study site ( 30\% bare rock spaces available at this level, B. K. K. Chan unpubl. data). Bulldozing by grazers may be responsible for the lack of recruitment (Chan \& Williams 2003) as the low shore of Cape d'Aguilar is colonized by a high density of grazers including the limpet Cellana toreuma and the chiton Acanthopleura japonica (Williams 1994).

\section{Physiological responses}

During calm, sunny, daytime low spring tides, barnacle body temperatures and haemolymph osmolality rose to maximum levels between noon and mid-afternoon, indicating that barnacles were under greater heat and desiccation stresses at this time. Rock temperature varied with different habitats, and barnacles on vertical surfaces had lower temperatures than those on horizontal surfaces, similar to observations for the high shore limpet Cellana grata (Williams \& Morritt 1995). 

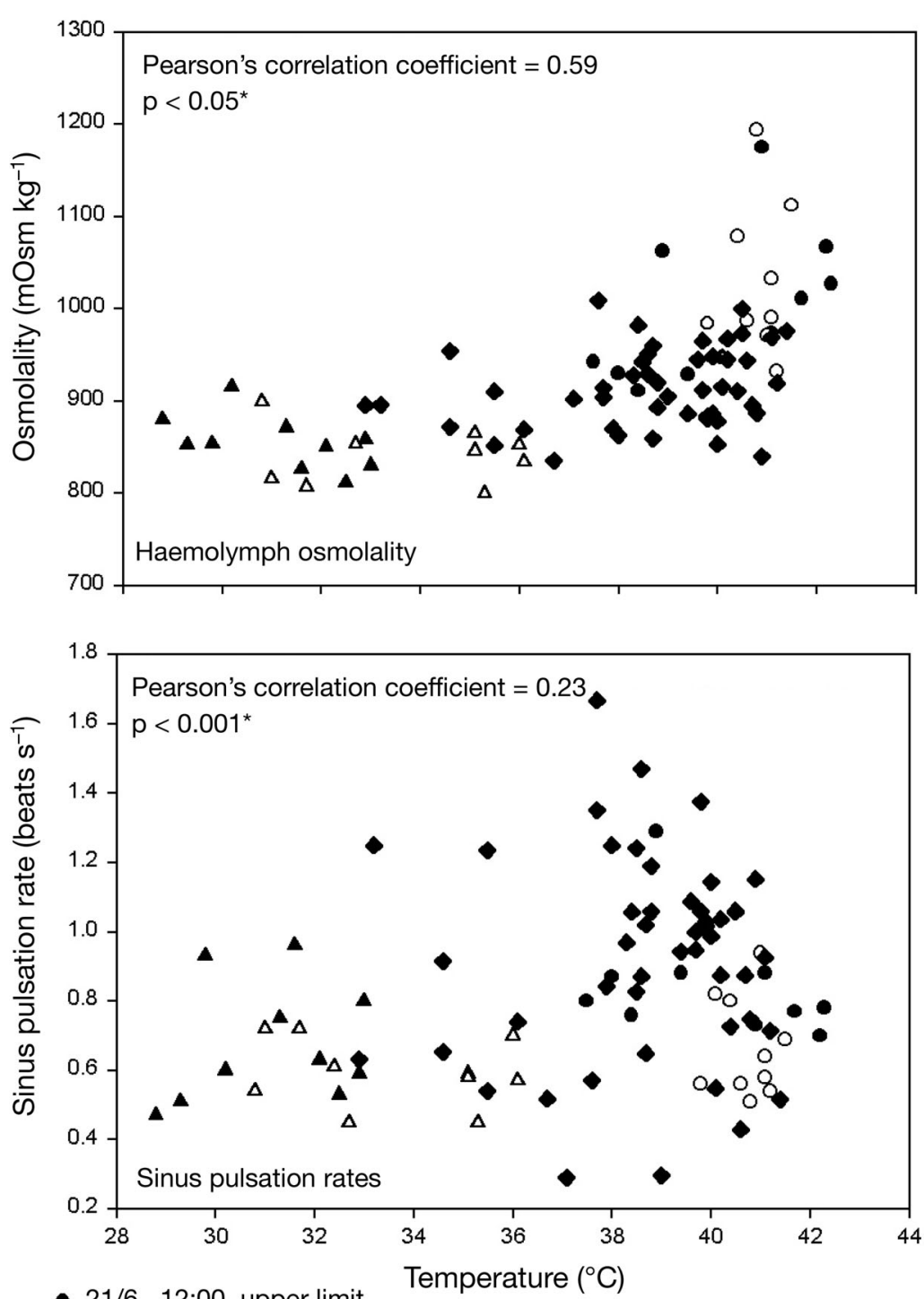

- 21/6, 12:00, upper limit

- 21/6, 16:00, upper limit

- 21/6, 12:00, Tetraclita-dominated zone

$\Delta$ 21/6, 16:00, Tetraclita-dominated zone

- 4/7, 13:00, Tetraclita-dominated zone

Fig. 6. Tetraclita japonica. Pearsons's correlation analysis $(\mathrm{n}=88)$ of haemolymph osmolality and sinus pulsation rate with body temperatures. Data pooled from measurements of the diurnal and spatial variations of physiological parameters $\left({ }^{*}\right.$ significant factors, $\left.\mathrm{p}<0.05\right)$

Heat and desiccation stress affect the hydroskeleton and physiology of barnacles. Barnacles generally have a high haemolymph pressure that helps maintain the hydroskeleton of their soft bodies (Walker \& Anderson 1990). As environmental temperatures increase, water is lost by evaporation from the haemolymph of Tetraclita japonica, which becomes more concentrated with increasing body temperatures (see Grainger \& Newell 1965, Foster 1969 for temperate examples). This is likely to reduce hydrostatic pressure, which may affect the hydroskeleton and, thus, impede normal function. The observed increase in sinus pulsation rate as barnacle temperatures increased may be either an attempt to increase haemolymph pressure after water loss due to evaporation or more likely a reflection of increased metabolic rate as a result of increased body temperature.

Reduction of haemolymph pressure due to water evaporation can further affect the strength of the adductor muscles (see Anderson 1994), which lose the ability to hold the opercular plates firmly closed. Because the plates remain open, the barnacles are subjected to prolonged heat stress. The opening of the opercular plates may, however, be a trade-off between the benefit of temperature reduction and the cost of increased desiccation (see Ware \& Hartnoll 1996), which will result in increased water loss (Barnes \& Barnes 1957, Anderson 1994). This loss will affect gaseous exchange and ultimately lead to hypoxic conditions (see Barnes et al. 1963, Davenport \& Irwin 2003, Lopez et al. 2003). In Hong Kong, the limpet Cellana grata also exhibits a similar trade-off by lifting the shell from the rock to reveal the foot, causing a decrease in body temperature but an increase in mantle water loss, which can lead to mortality over prolonged low spring tides in summer (Williams et al. 2005).

Tetraclita japonica does not benefit from heat reduction by forming hummocks as some temperate barnacle species do (Bertness et al. 1998), as T. japonica densities are lower ( $60 \%$ mean coverage) resulting in bare rock surface between individuals. Barnacle body temperatures were consistently 4 to $6^{\circ} \mathrm{C}$ higher than rock surface temperatures, probably a result of the barnacle body receiving heat directly from solar radiation as well as by conduction from the bedrock. The adjacent rock surface is probably cooler than the barnacle's body temperature as it is cooled by air movement (Williams \& Morritt 1995, Williams et al. 2005). The effect of air movement is, however, unlikely to cool barnacle internal temperatures. The barnacle's body is enclosed by the parieties and the opercular opening is closed by the valves, therefore effectively sealing the body within an insulated shell. The limpet Cellana grata (Williams et al. 2005) and various gastropods along Pacific Ocean coastlines (Vermiji 1971) have also been observed to 
have higher body temperatures than temperatures on the rock surfaces.

There was spatial variation in the heat and desiccation stress experienced by Tetraclita japonica. Rock temperature varied between habitats; barnacles on vertical surfaces had lower temperatures than those on horizontal surfaces, which is similar to observations made by Williams \& Morritt (1995) for the high shore limpet Cellana grata. On horizontal rocks, there was no variation in the body temperature or sinus pulsation rate of barnacles within 1 or $20 \mathrm{~m}$ on a horizontal spatial scale. Barnacle haemolymph osmolality, however, did vary over $20 \mathrm{~m}$, which may reflect spatial patterns or variation in the volume of mantle water trapped by individuals before emersion. This volume of water can buffer against the effects of evaporative water loss and, therefore, subsequent increase in haemolymph osmolality. Horizontal spatial variation in desiccation and evaporation of haemolymph is likely to be affected by many factors such as wind intensity, wave splash and air temperature, all of which often display great spatial variability (Harley \& Helmuth 2003).

On tropical shores, heat and desiccation stress have a predictable and strong effect on the distribution and ecology of the acorn barnacle. There is an annual heavy mortality event in the high shore during summer and pulse recruitment occurs after this in the late summer. Menge (2000) suggested that the relative importance of recruitment and post-recruitment processes were dependent on species and geographic location (also see Roughgarden et al. 1988). In the present study, both recruitment and post-recruitment mortality are important in affecting the demography of Tetraclita japonica. Pulse recruitment occurs in late summer, which re-establishes the $T$. japonica population after intense summer mortality. The population structure and distribution pattern are then affected by intense heat and desiccation stress in the following summer and, in the high shore, individuals $<1$ yr old are killed before they can reach sexual maturity. Heat stress, therefore, controls the upper limit and fitness of these individuals and sets the upper vertical distribution of $T$. japonica on shores with similar wave exposure in Hong Kong (Chan et al. 2001). In the mid-shore, barnacles experience less stress and mortality is size-dependent, with the younger cohort suffering greater mortality than older cohorts. Recruit density and population demography in the mid-shore are also affected by physical stress and this effect shows some degree of spatial variation, probably in response to local changes in wave splash and topography. This annual pattern of heavy mortality and subsequent pulse recruitment, therefore, has a strong influence on the population dynamics and overall life history patterns of T. japonica on seasonal tropical shores.
Acknowledgements. The authors thank Janet K. W. Lee, Shirley C. Y. Chow and Cecily C. L. Law for excellent assistance in field work and technical aspects. Permission to work in the Cape d'Aguilar Marine Reserve was granted by the Agriculture, Fisheries and Conservation Department, Hong Kong SAR Government. K.M.Y.L. was supported by the Croucher Foundation, Hong Kong, and D.M. acknowledges financial support from the Royal Society (UK). D.M. and M.D.P. are grateful to The Swire Institute of Marine Science and Department of Ecology \& Biodiversity, The University of Hong Kong, for providing accommodation and research facilities.

\section{LITERATURE CITED}

Anderson DT (1994) Barnacles: structure, function, development and evolution. Chapman \& Hall, London

Barnes H, Barnes M (1957) Resistance to desiccation in intertidal barnacles. Science 126:358

Barnes M (1999) The mortality of intertidal cirripedes. Oceanogr Mar Biol Annu Rev 37:153-244

Barnes M, Finlayson DM, Piatigotsky J (1963) The effect of desiccation and anaerobic conditions on the behaviour, survival and general distribution of three common cirripedes. J Anim Ecol 32:233-252

Bertness MD (1989) Intraspecific competition and facilitation in a northern acorn barnacle population. Ecology 70 : 257-268

Bertness MD, Gaines SD, Yeh SM (1998) Making mountains out of barnacles: the dynamics of acorn barnacle hummocking. Ecology 79:1382-1394

Bertness MD, Leonard GH, Levine JM, Bruno JF (1999) Climate-driven interactions among rocky intertidal organisms caught between a rock and a hot place. Oecologia 120:446-450

Cai R, Huang Z (1986) The reproductive characteristics of some Cirripedia in Hong Kong waters. In: Morton B (ed) The marine flora and fauna of Hong Kong and Southern China II. Proceedings of the second international marine biological workshop: the marine flora and fauna of Hong Kong and Southern China, Hong Kong, 1986. Hong Kong University Press, Hong Kong, p 945-960

Chan BKK (2001) Studies on Tetraclita squamosa and Tetraclita japonica. I: Adult morphology. J Crustac Biol 21: 616-630

Chan BKK (2003) Studies on Tetraclita squamosa and Tetraclita japonica. II: Larval morphology and development. J Crustac Biol 23:522-547

Chan BKK, Williams GA (2003) The impact of physical stress and molluscan grazing on the settlement and recruitment of Tetraclita species (Cirripedia: Balanomorpha) on a tropical shore. J Exp Mar Biol Ecol 284:1-23

Chan BKK, Williams GA (2004) Population dynamics of the acorn barnacles, Tetraclita squamosa and Tetraclita japonica (Cirripedia: Balanomorpha) in Hong Kong. Mar Biol 146:149-160

Chan BKK, Morritt D, Williams GA (2001) Effect of salinity and recruitment on the distribution of Tetraclita squamosa and Tetraclita japonica in Hong Kong. Mar Biol 138:99-109

Chelazzi G, Williams GA, Gray DG (1999) Field and laboratory measurement of respiratory pulsation rate in a tropical limpet. J Mar Biol Assoc UK 284:1-23

Crisp DJ, Southward AJ (1961) Different types of cirral activity of barnacles. Phil Trans R Soc Lond B Biol Sci 243: 271-308

Davenport J, Irwin S (2003) Hypoxic life of intertidal acorn barnacles. Mar Biol 143:555-563 
Depledge MH, Anderson BB (1990) A computer-aided physiological monitoring system for continuous, long term recording of cardiac activity in selected invertebrates. Comp Biochem Physiol 96:474-477

Ellis DV, Wilce RT (1961) Arctic and subarctic examples of intertidal zonation. Arctic 14:224-235

Foster BA (1969) Tolerance of high temperature by some intertidal barnacles. Mar Biol 4:326-332

Foster BA (1971) Desiccation as a factor in the intertidal zonation of barnacles. Mar Biol 8:12-29

Garrity SD (1984) Some adaptations of gastropods to physical stress on a tropical rocky shore. Ecology 65:559-574

Grainger F, Newell GE (1965) Aerial respiration in Balanus balanoides. J Mar Biol Assoc UK 45:469-479

Harley CDG, Helmuth BST (2003) Local and regional-scale effects of wave exposure, thermal stress, and absolute versus effective shore level on patterns of intertidal zonation. Limnol Oceanogr 48:1498-1508

Helmuth BST (1998) Intertidal mussel microclimates: predicting the body temperature of a sessile invertebrate. Ecol Monogr 68:51-74

Helmuth BST, Hofmann GE (2001) Microhabitats, thermal heterogeneity and patterns of physiological stress in the rocky intertidal zone. Biol Bull 201:374-384

Kaehler S, Williams GA (1996) Distribution of algae on tropical rocky shores: spatial and temporal patterns of noncoralline algae in Hong Kong. Mar Biol 125:177-187

Lopez DA, Castro JM, Gonzalez ML, Simpfendorfer RW (2003) Physiological responses to hypoxia and anoxia in the giant barnacle, Austromegabalanus psittacus (Molina, 1782). Crustaceana 76:535-545

McCook LJ, Chapman ARO (1997) Patterns and variations in natural succession following massive ice-scour of a rocky intertidal seashore. J Exp Mar Biol Ecol 214:121-147

Menge BA (2000) Recruitment vs. postrecruitment processes as determinants of barnacle population abundance. Ecol Monogr 70:265-288

Menge BA, Southerland JP (1987) Community regulation: variation in disturbance, competition, and predation in relation to environment stress and recruitment. Am Nat 130:730-757

Morton B, Williams GA, Lee SY (1996) The benthic marine ecology of Hong Kong: a dwindling heritage? In: Coastal infrastructure development in Hong Kong: a review. Proceedings of the symposium on the hydraulics of Hong

Editorial responsibility: Otto Kinne (Editor-in-Chief), Oldendorf/Luhe, Germany
Kong waters. Hong Kong Government Printer, Hong Kong, p 233-268

Roughgarden J, Gaines SD, Possingham H (1988) Recruitment dynamics in complex life cycles. Science 241: 1460-1466

Southward AJ (1958) Note on the temperature tolerance of some intertidal animals in relation to environmental temperatures and geographic distribution. J Mar Biol Assoc UK 37:49-66

Southward AJ (1962) On the behaviour of barnacles. IV: The influences of temperature on cirral activity and survival of some warm-water species. J Mar Biol Assoc UK 42: 163-177

Sutherland JP (1987) Recruitment limitation in a tropical intertidal barnacle: Tetraclita panamensis on the Pacific coast of Costa Rica. J Exp Mar Biol Ecol 113:267-282

Vermiji GJ (1971) Temperature relationships of some tropical Pacific intertidal gastropods. Mar Biol 10:308-314

Walker G, Anderson DT (1990) Haemolymph pressures in barnacles: a comparative study. Proc R Soc Lond B Biol Sci 240:1-14

Ware FJ, Hartnoll RG (1996) Desiccation tolerance of the barnacle Semibalanus balanoides in relation to shore height (Cirripedia, Thoracica). Crustaceana 69:321-329

Wethey DS (1984) Sun and shade mediate competition in the barnacles Chthamalus and Semibalanus in New England. Biol Bull 165:330-341

Williams GA (1994) The relationship between shade and molluscan grazing in structuring communities on a moderately-exposed tropical rocky shore. J Exp Mar Biol Ecol 178:79-85

Williams GA, McMahon BR (1998) Haemolymph pH and oxygen levels in a naturally stressed tropical limpet, Cellana grata. In: Morton B (ed) The marine biology of the South China Sea. Proceedings of the third international conference on the marine biology of the South China Sea, Hong Kong 28 October-1 November 1996. Hong Kong University Press, Hong Kong, p 239-245

Williams GA, Morritt D (1995) Habitat partitioning and thermal tolerance in a tropical limpet, Cellana grata. Mar Ecol Prog Ser 178:79-85

Williams GA, Pirro MD, Leung KMY, Morritt D (2005) Physiological responses to heat stress on a tropical shore, the benefits of mushrooming behaviour in the limpet Cellana grata. Mar Ecol Prog Ser 292:213-224

Submitted: February 17, 2006; Accepted: May 2, 2006 Proofs received from author(s): November 21, 2006 